\title{
Translocation as a conservation tool to supplement relict bat colonies: a pioneer study with endangered horseshoe bats
}

\author{
Irene C. Weinberger ${ }^{1, *}$, Fabio Bontadina ${ }^{1,2}$, Raphaël Arlettaz ${ }^{1}$ \\ ${ }^{1}$ Institute of Ecology and Evolution, Division of Conservation Biology, University of Bern, Baltzerstrasse 6, \\ 3012 Bern, Switzerland \\ ${ }^{2}$ SWILD, Urban Ecology \& Wildlife Research, Wuhrstrasse 12, 8003 Zürich, Switzerland
}

\begin{abstract}
Relocation has become an important tool in conservation biology. So far little is known about the suitability of translocation to restore bat populations. We evaluated the conditions for successful translocations amongst 2 bat species: the greater horseshoe bat Rhinolophus ferrumequinum and the lesser horseshoe bat $R$. hipposideros. Both species underwent a dramatic decline in Western and Central Europe in the second half of the 20th century, but some populations have recently started to recover. Due to their sedentary habits, natural recolonisation of their formerly vast inhabited range advances only slowly. Translocation could solve this problem. In 2006, we conducted translocation experiments with 11 greater and 7 lesser horseshoe bats within Switzerland. Bats were captured at large colonies, released into relict colonies, radiotracked for up to $10 \mathrm{~d}$ and checked for presence during the following years. Ten out of the 13 individuals released at distances $<20 \mathrm{~km}$ from the donor roost homed. None of the 5 bats released at distances $>40 \mathrm{~km}$ expressed homing tendencies. Within $3 \mathrm{~d}$ of release, 1 greater and 3 lesser horseshoe bats died ( 2 of shock). Lesser horseshoe bats seem to react very sensitively to translocation. Long-distance translocation of 2 greater horseshoe bats led to short-term settlement in the release area; since its translocation, the sole female released at long distance has been regularly observed in the receiver colony. Apparent species-specific differences in tolerance to translocation underline the necessity of studying the focal species instead of surrogate species in translocation projects.
\end{abstract}

KEY WORDS: Supplementation - Relocation - Switzerland - Rhinolophus ferrumequinum • Rhinolophus hipposideros

\section{INTRODUCTION}

Conservation biologists aim at identifying major factors behind population declines so as to propose sound guidelines to remove or mitigate the causes of biodiversity erosion (Norris 2004). Locally implemented preservation measures may halt the decline of endangered populations, but if the size of the latter has already fallen below a minimum viable threshold, typical symptoms of small population sizes can obliterate these efforts, e.g. inbreeding depression, loss of genetic diversity and demographic stochasticity
(Frankham 2005). When immigration is unlikely due to the isolated nature of the population, the intentional release of additional individuals (captive-reared or wild) may be a last option to avoid local extinction. So far, most experimental supplementations have dealt with birds or terrestrial mammals, and few with amphibians, reptiles or invertebrates (Fischer \& Lindenmayer 2000). Indeed, bats, which are very much affected by anthropogenic perturbations (Mickleburgh et al. 2002), have rarely been subject to deliberate translocations (Kramer 1971, Richarz 1989, Guilbert et al. 2007, Ruffell \& Parsons 2009, this Theme Section), 
and most reports concern accidental translocations or homing experiments (e.g. Davis 1966, Constantine 2003, Holland et al. 2006).

Since World War II, the greater horseshoe bat Rhinolophus ferrumequinum and the lesser horseshoe bat $R$. hipposideros have undergone dramatic declines in Central and Western Europe, including Switzerland (Roer 1983, Stebbings \& Arnold 1989, Bontadina et al. 2000, Schaub et al. 2007). The populations of the greater horseshoe bat in Switzerland-once widespread, although never very common, across the country - shrank to only 4 isolated colonies (Schaub et al. 2007). The most likely causes of decline of the species appear to be pesticides, habitat changes, food shortage and loss and deterioration of roosts (Stebbings \& Arnold 1989). The decline of the lesser horseshoe bat has been even more severe: this species was once very common and abundant throughout the country, whilst only isolated populations remain today in remote regions of the Alps (Stutz \& Haffner 1984, Bontadina et al. 2000). The main probable factor in the decline of lesser horseshoe bats in Switzerland was the use of organochlorine pesticides in the past (Bontadina et al. 2008, R. Arlettaz et al. unpubl. data).

The fact that several populations of both species have recently shown signs of recovery in Switzerland suggests that the causes of decline have to some extent disappeared, which, in the case of the lesser horseshoe bat, is compatible with the pesticide scenario mentioned above. Yet an expansion into historically inhabited areas, including the recolonisation of previously abandoned roosts, has not been documented so far. Natural recolonisation of former ranges would be hampered by the fragmented nature of the present habitat matrix, with many isolated populations in remote alpine valleys, and by the strong natal philopatry in females (Ransome 1995). Therefore the question that arises is whether the translocation of individuals from large colonies with positive population growth into small relict colonies could accelerate population expansion and help by mitigating any detrimental symptoms typical of small populations.

The aim of this pioneer work was to assess the feasibility of individual translocation as a potential tool for supplementing relict populations of the 2 horseshoe bat species. More specifically, we attempted to evaluate the minimum requested translocation distance as well as the most suitable age class for successful translocation. Based on the results of previous homing experiments (Davis 1966), we expected that adults would express a high homing tendency, whereas subadults and yearlings should be less imprinted geographically and socially, i.e. more prone to adapt to a new environment. However, survival might be lower for yearlings (Schaub et al. 2008). Survival and settle- ment of the translocated animals were evaluated in both short- (radiotracking) and mid-term (roost) surveys.

\section{MATERIALS AND METHODS}

Captures and releases. To reduce the effects of individual removal, translocated bats were only taken from large, increasing donor colonies ( $>50$ adults as per 2005). They were released into relict, often slightly augmenting colonies. This ensured that both roost and foraging habitats were not yet at carrying capacity. We attempted to assess the success of translocation according to the criteria outlined in Seddon (1999): (1) short-term settlement: animals stayed for a period of days in the release area; (2) mid-term settlement: bats successfully hibernated there; and (3) long-term settlement: bats reproduced in the receiver colony home range. Individuals of 3 age classes were used: adults, subadults ( 1 to 2 yr old) and yearlings. We preferentially chose females to translocate because they are more likely to return to maternity roosts than males, thus increasing the accuracy of assessment of translocation success.

Our donor colony of greater horseshoe bats was located in Vex (Canton of Valais, $961 \mathrm{~m}$ altitude, $\mathrm{n}=$ 95 adults in 2005; Schaub et al. 2007, Sierro et al. in press), whilst the 4 donor colonies of lesser horseshoe bats were located in Kleinteil (Obwalden, $589 \mathrm{~m}, \mathrm{n}=$ 315), Giswil (Obwalden, $539 \mathrm{~m}, \mathrm{n}=66$ ), Latterbach (Bern, $820 \mathrm{~m}, \mathrm{n}=66$ ) and Blumenstein (Bern, $833 \mathrm{~m}$, $\mathrm{n}=108$ ). All donor colonies were based in small alpine villages which are surrounded by various mountainous landscapes consisting of farmland and woodland.

For the release of the greater horseshoe bats, 2 receiver colonies with only few individuals were chosen: Pfyn (Valais, $616 \mathrm{~m}, \mathrm{n}=4$ ) and Wegenstetten (Aargau, $488 \mathrm{~m}, \mathrm{n}=5$ ). For the lesser horseshoe bats, release sites were selected among small populations ( $<45$ adults as per 2005): Brienzwiler (Bern, $729 \mathrm{~m}, \mathrm{n}=$ 44) and Wilen (Obwalden, $554 \mathrm{~m}, \mathrm{n}=33$ ). The distances between donor and receiver colonies are given in Table 1. We made sure that receiver colonies were in buildings and mountainous landscapes similar to the surroundings of the donor colonies.

Greater horseshoe bats were captured with mistnets in May (adults), July (subadults) and September 2006 (yearlings) outside the donor roost or at the entrance to a cave used as a day roost by the same colony (Lugon 1996). Lesser horseshoe bats were captured in June (adults) and August 2006 (subadults and yearlings) either with mist-nets at the roost entrance or with a hand-net within the nursery roost after sun- 
Table 1. Rhinolophus ferrumequinum and R. hipposideros. Number of bats used for translocation (N) with information on donor and receiver colonies with respect to colony size and aerial distance between them. GHB: greater horseshoe bat; LHB: lesser horseshoe bat. Donor colony size of the Vex colony was estimated from mark-recapture modelling (Schaub et al. 2007); all other donor colony sizes were estimated from the maximum number of individuals at emergence before pups started to fly out of the nursery roost in 2005

\begin{tabular}{|c|c|c|c|c|c|c|c|c|}
\hline Species & Donor colony & Coordinates & Colony size & $\mathrm{N}$ & Receiver colony & Coordinates & Colony size & Distance $(\mathrm{km})$ \\
\hline GHB & Vex & $46^{\circ} 12^{\prime} \mathrm{N}, 7^{\circ} 23^{\prime} \mathrm{E}$ & 95 & 9 & Pfyn & $46^{\circ} 18^{\prime} \mathrm{N}, 7^{\circ} 36^{\prime} \mathrm{E}$ & 43 & 18 \\
\hline GHB & Vex & $46^{\circ} 12^{\prime} \mathrm{N}, 7^{\circ} 23^{\prime} \mathrm{E}$ & 95 & 2 & Wegenstetten & $47^{\circ} 29^{\prime} \mathrm{N}, 7^{\circ} 55^{\prime} \mathrm{E}$ & 5 & 148.6 \\
\hline LHB & Giswil & $46^{\circ} 50^{\prime} \mathrm{N}, 8^{\circ} 11^{\prime} \mathrm{E}$ & 66 & 3 & Brienzwiler & $46^{\circ} 44^{\prime} \mathrm{N}, 8^{\circ} 5^{\prime} \mathrm{E}$ & 44 & 12.3 \\
\hline LHB & Blumenstein & $46^{\circ} 43^{\prime} \mathrm{N}, 7^{\circ} 30^{\prime} \mathrm{E}$ & 108 & 1 & Brienzwiler & $46^{\circ} 44^{\prime} \mathrm{N}, 8^{\circ} 5^{\prime} \mathrm{E}$ & 44 & 44.3 \\
\hline LHB & Latterbach & $46^{\circ} 40^{\prime} \mathrm{N}, 7^{\circ} 34^{\prime} \mathrm{E}$ & 66 & 1 & Wilen & $46^{\circ} 52^{\prime} \mathrm{N}, 8^{\circ} 13^{\prime} \mathrm{E}$ & 33 & 54.3 \\
\hline LHB & Blumenstein & $46^{\circ} 43^{\prime} \mathrm{N}, 7^{\circ} 30^{\prime} \mathrm{E}$ & 108 & 1 & Wilen & $46^{\circ} 52^{\prime} \mathrm{N}, 8^{\circ} 13^{\prime} \mathrm{E}$ & 33 & 56.8 \\
\hline LHB & Kleinteil & $46^{\circ} 49^{\prime} \mathrm{N}, 8^{\circ} 9^{\prime} \mathrm{E}$ & 315 & 1 & Brienzwiler & $46^{\circ} 44^{\prime} \mathrm{N}, 8^{\circ} 5^{\prime} \mathrm{E}$ & 44 & 10.5 \\
\hline
\end{tabular}

rise. During the period of late pregnancy and early lactation, no animal of either species was captured in order to keep disturbance to a minimum. No animal was translocated prior to bad weather and translocations ended at the end of September, i.e. well before the onset of hibernation.

All captured animals were sexed, measured and their reproductive status was assessed. The exact age of greater horseshoe bats was known beforehand because since 1989 all yearly cohorts had been ringed at Vex (Schaub et al. 2007, Sierro et al. in press). Only healthy bats were chosen and - in the rare case where they were not already marked - were ringed. They were fitted with a radio transmitter (Holohil Systems) which was attached to the fur between the shoulder blades with Skinbond ${ }^{\mathrm{TM}}$, a latex-based and biodegradable surgical glue. Adult and subadult greater horseshoe bats were equipped with $\mathrm{BD}-2 \mathrm{P}$ transmitters (1.0 g, activity switch, $28 \mathrm{~d}$ life expectancy); lesser horseshoe bats and yearlings of greater horseshoe bats were fitted with BD-2N transmitters ( $0.43 \mathrm{~g}$, no activity switch, $14 \mathrm{~d}$ life expectancy). Forearm wing bands and transmitters were both covered with colour reflecting tape to enable visual recognition with a torch from a distance. At first, captured animals were kept in linen bags or small cages $(30 \times 30 \times 30 \mathrm{~cm})$ and stored in a dark and cool place. Water was provided ad libitum in the cage. During transport to the receiver colony, which lasted between $20 \mathrm{~min}$ and $3 \mathrm{~h}$, animals were kept in bags only. To increase the duration of contact with the local conspecifics within the roost, all bats were released within the receiver roost within $4 \mathrm{~h}$ after sunrise. Of all translocated bats, $67 \%$ (greater horseshoe bats, $\mathrm{n}=7$; lesser horseshoe bats, $\mathrm{n}=5$ ) were captured in early morning, with captivity thus lasting less than $4 \mathrm{~h}$; the remaining $33 \%$ (greater horseshoe bats, $\mathrm{n}=4$; lesser horseshoe bats, $\mathrm{n}=2$ ) were captured at dusk emergence, which implied up to $12 \mathrm{~h}$ of captivity.

Monitoring translocation success. To detect possible agonistic interactions between resident bats and the immigrants, bat behaviour was monitored during the day of release until dusk emergence (greater horseshoe bats, $\mathrm{n}=2$; lesser horseshoe bats, $\mathrm{n}=4$ ) with an infrared video recording system (Videotronic, CCD7012P; tape recorder: Sanyo, TLS 9924P with a 10 frames $\mathrm{s}^{-1}$ time-lapse; $80 \mathrm{~W}$ infrared LED light: MFLI/LED6). The camera was pointed towards the area where most bats roosted. Video footage was subsequently analysed in the lab.

After dusk emergence, all bats were continuously radiotracked during the whole night by one person equipped with a receiver (Australis 26k scanning receiver, Titley Electronics) and a directional $\mathrm{H}$ antenna (RA-14K, Telonics), or a vehicle-mounted omnidirectional antenna (HL-M881H, Hotline). Foraging areas were located by homing in towards the highest amplitude signals (White \& Garrott 1990). Coordinates of bearings were taken with GPS (eTrex Summit, Garmin). In some instances, bats could be observed in the field, either visually, using a torch with a red light filter, or by using a bat detector (Mini-3 Bat detector, Ultra Sound Advice). Individuals were followed for up to 10 consecutive nights, but continuous radio-monitoring was restricted to the first 3 initial nights when animals homed. Locations of day roosts were assessed until the transmitter failed or was removed or when the bat died.

Monitoring is still ongoing (as of 2009), with presence being regularly checked in the receiver roost as well as in all roosts that were visited at least once during the translocation experiment, providing information about the mid-term success.

Statistical analysis. As translocation distances varied greatly for lesser horseshoe bats and also to simplify, we grouped the distances into 2 classes: $<20 \mathrm{~km}$ and $>40 \mathrm{~km}$ (Table 1). Four dispersal directions (N, E, S and W) were estimated through bearings of vanishing signals and tested for non-random directionality of movement by applying a chi-square test on the number of moves into each of 4 azimuth quadrants. The flight 
speed in greater horseshoe bats was calculated from the time of emergence until the animal crossed an arbitrary border of their colonial home range $(4 \mathrm{~km}$ radius from the nursery colony, based on radiotracking data obtained for the donor colony by Lugon 1996). Statistics are presented as means $\pm \mathrm{SE}$.

\section{RESULTS}

\section{Greater horseshoe bats}

Eleven greater horseshoe bats were translocated: 4 adult females and 5 yearlings ( 2 females and 3 males) over an aerial distance of $18 \mathrm{~km}$ between the donor and receiver roosts, whilst 2 subadults (1 female and 1 male) were released $148 \mathrm{~km}$ away (Fig. 1).

Video filming in the roost was only carried out for the 2 subadult bats released $148 \mathrm{~km}$ from their donor roost. The video footage comprised 320 min of sequences, but only the translocated female could be recognized, and only for $12 \mathrm{~s}$ : it hung close to a resident bat, but neither body contact nor agonistic behaviour could be observed. In the first night after release, emergence time was slightly delayed, on average by $27.5 \mathrm{~min}$ (range $=-4$ to $82 \min ; \mathrm{n}=11$ ), compared to the emergence time in the subsequent evening. During the first night after release, only 1 greater horseshoe bat used the release site as a night roost, and this may have been due to a heavy rainfall.

All 9 bats translocated $18 \mathrm{~km}$ away from the donor roost showed homing tendencies, at least initially. Movement towards original nursery roosts was recognised starting as early as $126 \pm 45.4 \min (\mathrm{n}=9)$ after emergence on the very first night after release. Vanishing bearings were not randomly distributed according to the 4 azimuth quadrants $\left(\chi^{2}=20.25\right.$, df $\left.=3, p<0.05\right)$, with the approximate direction always pointing towards the donor roost. Eight out of these 9 bats completed homing within the first night after release. The time span between the emergence at the release site and the crossing of the boundary of the foraging home range of their colony of origin averaged $173.5 \pm$ $10.6 \mathrm{~min}(\mathrm{n}=8)$, resulting in a mean flight speed of $7.7 \pm 2.2 \mathrm{~km} \mathrm{~h}^{-1}$ with a maximum recorded speed of $21 \mathrm{~km} \mathrm{~h}^{-1}$. Interestingly, all adult bats that homed did not use their native nursery roost for at least $2 \mathrm{~d}$ after release. With regard to the yearlings, 3 returned to the donor roost immediately after homing, whilst one did so only during the second night after release. All bats that had returned to their place of origin foraged exclusively within a radius of $3.9 \mathrm{~km}$ from nursery roost, which corresponds to the previously estimated foraging home range of the colony (Lugon 1996).

The 2 subadult bats released $148 \mathrm{~km}$ away from their place of origin stayed in the surroundings of the release

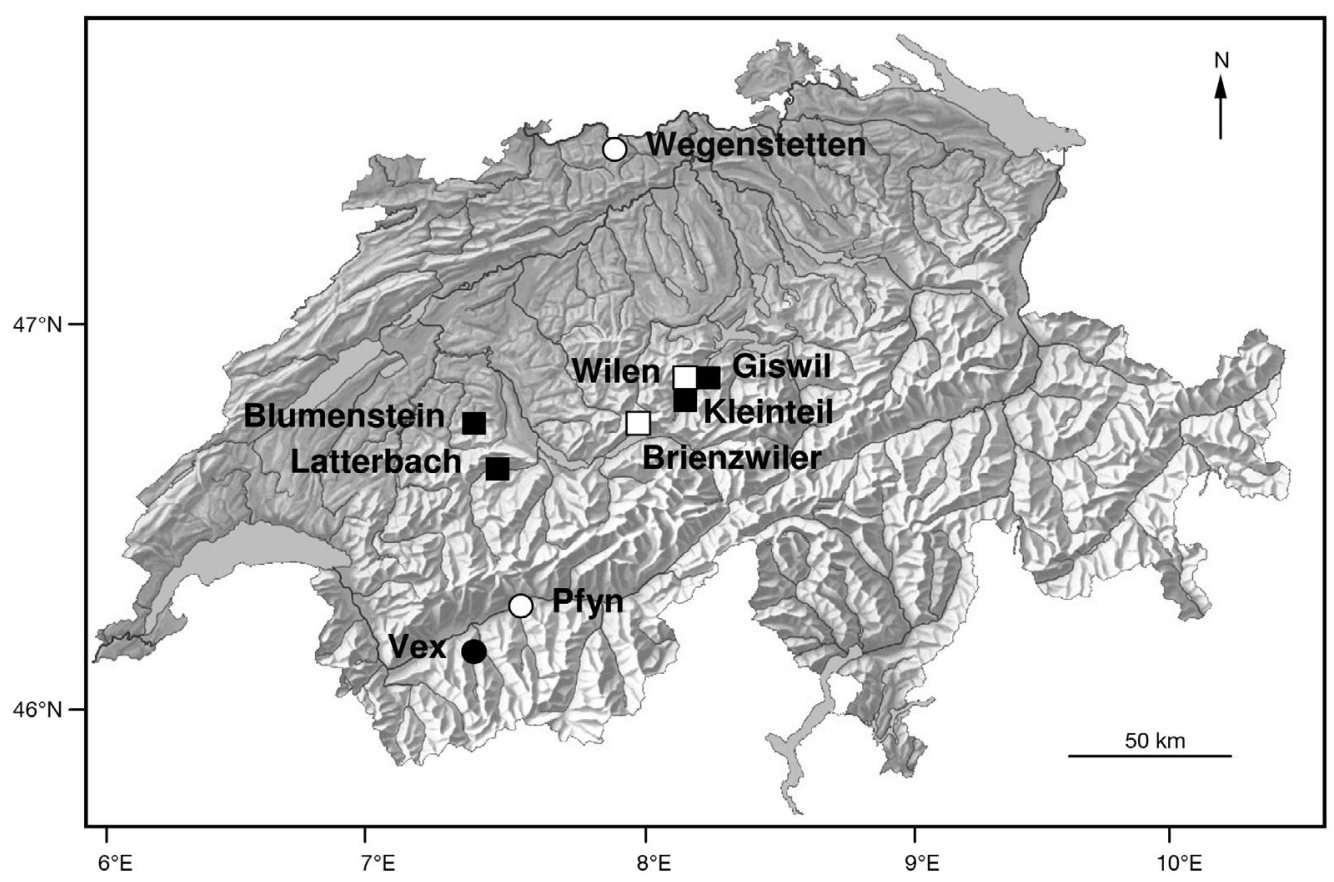

Fig. 1. Rhinolophus ferrumequinum and R. hipposideros. Nursery roosts of greater (GHB, circles) and lesser horseshoe bats (LHB, squares) used for translocation experiments in Switzerland. Black symbols: donor colonies; white symbols: receiver colonies. GHB were translocated from Vex to Pfyn (18 km aerial distance) and from Vex to Wegenstetten (148 km). LHB were released in Brienzwiler, stemming from Blumenstein $(44 \mathrm{~km})$, Giswil $(12 \mathrm{~km})$ and Kleinteil $(10 \mathrm{~km})$; and in Wilen, originating from Latterbach $(54 \mathrm{~km})$ and Blumenstein $(56 \mathrm{~km})$ 
Table 2. Rhinolophus ferrumequinum and R. hipposideros. Short-term translocation outcome for all translocated bats. For bats settling down in the release area (remaining at least 1 night in the release area), the maximal distances from the release site to main foraging grounds and settlement roosts are indicated. GHB: greater horseshoe bat; LHB: lesser horseshoe bat; F: female; M: male; A: adult; S: subadult; J: juvenile; +: success; - failure

\begin{tabular}{|c|c|c|c|c|c|c|c|}
\hline Species & Sex & Age class & $\begin{array}{c}\text { Distance } \\
\text { capture-release } \\
\text { location }(\mathrm{km})\end{array}$ & $\begin{array}{l}\text { Immediate } \\
\text { translocation } \\
\text { outcome }\end{array}$ & $\begin{array}{l}\text { Reason for } \\
\text { failure }\end{array}$ & $\begin{array}{l}\text { Max distance from } \\
\text { release site to } \\
\text { foraging ground }(\mathrm{km})\end{array}$ & $\begin{array}{l}\text { Max distance } \\
\text { from release site to } \\
\text { chosen roost }(\mathrm{km})\end{array}$ \\
\hline GHB & $\mathrm{F}$ & A & 18 & - & Immediate homing & & \\
\hline GHB & $\mathrm{F}$ & A & 18 & - & Immediate homing & & \\
\hline GHB & $\mathrm{F}$ & A & 18 & - & Immediate homing & & \\
\hline GHB & $\mathrm{F}$ & A & 18 & - & Immediate homing & & \\
\hline GHB & $\mathrm{F}$ & $\mathrm{S}$ & 148.6 & + & & 1.3 & 0.2 \\
\hline GHB & $\mathrm{M}$ & $\mathrm{S}$ & 148.6 & + & & 10.4 & 9.9 \\
\hline GHB & M & $\mathrm{J}$ & 18 & - & Immediate homing & & \\
\hline GHB & M & $\mathrm{J}$ & 18 & - & Death (3rd night) & 5.2 & 4.7 \\
\hline GHB & M & $\mathrm{J}$ & 18 & - & Immediate homing & & \\
\hline GHB & $\mathrm{F}$ & $\mathrm{J}$ & 18 & - & Immediate homing & & \\
\hline GHB & M & $\mathrm{J}$ & 18 & - & Immediate homing & & \\
\hline LHB & $\mathrm{F}$ & $\mathrm{A}$ & 12.3 & - & Death (2nd night) & 0.4 & 0.46 \\
\hline LHB & $\mathrm{F}$ & A & 12.3 & - & Immediate homing & & \\
\hline LHB & $\mathrm{F}$ & A & 12.3 & - & Homing (2nd night) & 0.6 & 0.26 \\
\hline LHB & $\mathrm{F}$ & A & 44.3 & - & Death (3rd night) & 1.5 & 1.47 \\
\hline LHB & $\mathrm{F}$ & $\mathrm{S}$ & 54.3 & + & & 0.8 & 0.25 \\
\hline LHB & $\mathrm{F}$ & $\mathrm{S}$ & 56.8 & + & & 0.3 & 0.25 \\
\hline LHB & M & $\mathrm{J}$ & 10.5 & - & Death (1st night) & & \\
\hline
\end{tabular}

site until the end of their radiotracking sessions (Table 2). Among the short-distance releases, one yearling initially showed homing tendencies but eventually installed itself close to the release site where it was found on the ground partly eaten by a predator on Day 3 . None of these 3 bats that remained in the surroundings of the release area (the 2 long-distance and 1 short-distance translocations mentioned above) used the release site as day roost during the short-term monitoring; instead, they chose buildings close by. While the short-distance translocated yearling that did not home and died on Day 3 and the long-distance translocated subadult female roosted and foraged close to the release site, the roosts and foraging areas of the long-distance translocated subadult male were outside the suspected boundaries of the receiver colony home range (Table 2). During radiotracking, the 2 longdistance translocated subadult bats frequented only one roost each, for both day and night roosting.

The long-distance translocated subadult female was frequently observed in its new roost during the 2 yr following translocation (2007 and 2008). Pregnancy failure (loss of embryo) was documented on video footage for this bat in 2007 .

\section{Lesser horseshoe bats}

A total of 7 lesser horseshoe bats were translocated: 3 adult females and 1 yearling male, and 1 adult and 2 subadult females at aerial distances $<20$ and $>40 \mathrm{~km}$ from their original roosts, respectively (Tables 1 \& 2, Fig. 1).

A total of 650 min of video footage was obtained from 4 bats, of which 146.20 min of sequences showed a translocated bat. Altogether, 5 interactions were recorded: in 4 cases, a flying resident bat approached the sleeping translocated bat. Although agonistic behaviour cannot be entirely excluded, none of the translocated bats took off during or immediately after the approach. In one sequence, an introduced lesser horseshoe bat attached itself to the cluster of resident bats for a few seconds and then hung very close to the cluster without any noticeable agonistic behaviour from the residents.

Emergence was, as in greater horseshoe bats, slightly delayed, on average by $20 \mathrm{~min}$ (range $=-6$ to 30 min, $\mathrm{n}=6$ ) during the first night following the release compared to the emergence in the subsequent evening.

Two of the 4 lesser horseshoe bats translocated $<20 \mathrm{~km}$ homed: in one case, homing began $85 \mathrm{~min}$ after emergence on the first night; in the other case, immediately after emerging from a cave in the vicinity of the release site on the second night. The remaining 5 lesser horseshoe bats stayed in the surroundings of the release site throughout the whole period of radiotracking (two had been released $<20 \mathrm{~km}$ and three $>40 \mathrm{~km}$ from their original roost; Table 2). Bats that remained in the release area chose caves, rock 
crevices and buildings at maximum distances of $1.5 \mathrm{~km}$ from the release site, but none used the latter as a day roost. All roosted and foraged within the suspected foraging home range of their colony (Table 2).

During the short period of radiotracking, 3 of the 7 translocated bats died (on Days 1, 2 and 3, respectively). Two deaths that took place during daytime were diagnosed through necropsy as due to shock caused by stress. The third bat died at night, and its body was retrieved partly eaten.

\section{DISCUSSION}

Our pioneer work suggests that translocation of greater horseshoe bats might be a suitable measure for supplementing populations, provided that long-distance translocation is implemented: a subadult female was observed for over $2 \mathrm{yr}$ in the receiver colony, where it even attempted to reproduce in the year following its release. The fact that the subadult male released over the same distance was not re-observed is not surprising, as maturing males rarely share roosts with females (Schaub et al. 2007). In contrast, shortdistance translocations were a total failure among this species. For lesser horseshoe bats, all short-distance attempts failed, and 2 out of 3 bats translocated over long-distance remained in the area during short-term radiotracking. So far, these 2 bats have not been observed during mid-term monitoring.

In both species, agonistic behaviour between resident and translocated bats could not be documented. On this topic, information remains scarce. This differs remarkably from the defensive and aggressive reactions described in the strong matrilineal colonies of Bechstein's bats (Kerth et al. 2002).

After being released, none of the translocated bats used the release site as a day roost during the short period of radiotracking. Lesser horseshoe bats that remained in the release area used foraging grounds and roosts within the suspected foraging home range, which is estimated to lie within $2.5 \mathrm{~km}$ radius from the colony (Bontadina et al. 2002). Similarly, 2 of the 3 greater horseshoe bats that stayed in the release area remained within the $4 \mathrm{~km}$ radius of the estimated foraging home range of the colony (Jones et al. 1995, Lugon 1996). The third individual roosted and foraged outside the predicted foraging home range although it was at a short distance. The fact that at least 1 of 2 long-distance translocations of greater horseshoe bats resulted in mid-term installation and even reproduction attempts shows not only that greater horseshoe bats are able to find suitable foraging grounds and hibernacula in an initially totally unknown environment, but also that translocated bats can readily be accepted by residents.
The homing capacity of greater horseshoe bats released at short distance is also clearly demonstrated in the present study. Among 9 greater horseshoe bats released $18 \mathrm{~km}$ from their original nursery roost, all but one homed with ease. Casual sightings of banded individuals have shown that post-breeding dispersal of the greater horseshoe bats from the Vex colony can be as far as $27 \mathrm{~km}$ (Lugon 1996), suggesting that some of the translocated adult greater horseshoe bats might already have been familiar with the grounds around the release site. However, yearlings were most probably unfamiliar with the environment between the receiver and the donor roosts because they had not yet experienced post-breeding dispersal, and were likely still in the phase of gradually becoming acquainted with the nursery roost's surroundings (Jones et al. 1995). Indeed, the surprisingly high homing success rate of yearlings in the present study suggests the use of subtle spatial orientation mechanisms, e.g. reliance on Earth's magnetic field (Holland et al. 2006).

The 2 lesser horseshoe bats that homed had to pass a mountain ridge situated at an altitude of $1000 \mathrm{~m}$, about $300 \mathrm{~m}$ higher than the release and receiver sites. Previous homing experiments have shown that lesser horseshoe bats are able to find their roost when released as far as $24 \mathrm{~km}$ from their original roost (Issel 1950, Davis 1966), and exceptional long-distance movements of up to $150 \mathrm{~km}$ have been documented from some banded individuals (Hutterer et al. 2005).

Earlier homing experiments with bats have revealed that even non-migratory species can locate their original roost over long distances (Davis 1966). Our results suggest that the minimum distance for a successful translocation of bats is much longer than the distance recommended for most terrestrial mammals, which has been estimated as 5 to 10 times the width of an individual's home range (Conover 2002).

The variation in homing velocities varied greatly between individuals because most bats foraged on their way home. Our estimated maximum flight speed of $21 \mathrm{~km} \mathrm{~h}^{-1}$ in one greater horseshoe bat corroborates the figures obtained by Stebbings (1982).

During our translocation experiments, 3 lesser horseshoe bats ( $43 \%)$ and 1 greater horseshoe bat $(9 \%)$ died within $3 \mathrm{~d}$ of release. Translocating wild animals involves frequent handling, e.g. capture, transmitter attachment, transportation and release, all of which are likely to induce some stress (Williams \& Thorne 1996, Jung et al. 2002). However, this high mortality rate, especially in lesser horseshoe bats, is unlikely to be attributed only to capture and handling; former radiotracking by our research group of $>50$ greater horseshoe bats and 50 lesser horseshoe bats within their native range led to no casualties (Bontadina et al. 1995, 2002, 2006, Lugon 1996). We thus believe that 
the deaths recorded in the present study were caused principally by exposure to a new and hostile environment (Letty et al. 2000), which may in turn, among other factors, have increased predation risks.

We conclude that lesser horseshoe bats may be too sensitive to be translocated. Other methods should thus be sought after to help them recolonise their former range (e.g. defragmentation of habitat as suggested by Bontadina et al. 2008). In contrast, there seems to be some potential for successful translocation in greater horseshoe bats, provided that only subadults or adults are released at great distances $(>100 \mathrm{~km})$ from their home site. A tight genetic monitoring of the supplemented colonies both before and after release would provide a unique opportunity to assess the effects of introducing new genes into relict populations for population development. Finally, our findings revealed contrasted species-specific differences in behaviour and adaptive potential to new environments in these 2 related bat species, underlining the necessity to study the endangered focal species-instead of surrogate species as proposed by the IUCN (1998)when considering translocation as an option for population restoration.

Acknowledgements. This work was only possible thanks to the engaged support of the regional bat coordinators A. Beck (Aargau), A. Sierro (Valais), A. Theiler (Obwalden) and P. Zingg (Bern). We thank M. P. Ryser of the Institute for Pathology, Vetsuisse faculty, University of Bern, for the necropsies. We are especially grateful to 3 anonymous reviewers for improvements to the paper. The experiments were performed under license from the Federal Ministry for the Environment and from the official cantonal agencies of Obwalden, Valais, Aargau and Bern.

\section{LITERATURE CITED}

Bontadina F, Beck A, Gloor S, Hotz T, Lutz M, Mühlethaler E (1995) Jagt die grosse Hufeisennase Rhinolophus ferrumequinum im Wald? Grundlagen zum Schutz der letzten grösseren Kolonie in der Schweiz. Ornithol Beob 92:325-327

Bontadina F, Arlettaz R, Fankhauser T, Lutz M, Mühlethaler E, Theiler A, Zingg P (2000) The lesser horseshoe bat Rhinolophus hipposideros in Switzerland: present status and research recommendations. Le Rhinolophe 14:69-83

Bontadina F, Schofield H, Naef-Daenzer B (2002) Radio tracking reveals that lesser horseshoe bats (Rhinolophus hipposideros) forage in woodland. J Zool Lond 258:281-290

Bontadina F, Hotz T, Märki K (2006) Die Kleine Hufeisennase im Aufwind. Ursachen der Bedrohung, Lebensraumansprüche und Förderung einer Fledermausart. Haupt Verlag, Bern

Bontadina F, Schmied SF, Beck A, Arlettaz R (2008) Changes in prey abundance unlikely to explain the demography of a critically endangered Central European bat. J Appl Ecol 45:641-648

Conover MR (2002) Wildlife translocation. In: Resolving human-wildlife conflicts: the science of wildlife dam- age management. Lewis Publishers, Boca Raton, FL, p 211-228

Constantine DG (2003) Geographic translocation of bats: known and potential problems. Emerg Infect Dis 9:17-21

- Davis R (1966) Homing performance and homing ability in bats. Ecol Monogr 36:201-237

- Fischer J, Lindenmayer DB (2000) An assessment of the published results of animal's relocations. Biol Conserv 96:1-11

Frankham R (2005) Genetics and extinction. Biol Conserv 126:131-140

Guilbert M, Walker MM, Greif S, Parsons S (2007) Evidence of homing following translocation of long-tailed bats (Chalinolobus tuberculatus) at Grand Canyon Cave, New Zealand. N Z J Zool 34:239-246

Holland RA, Thorup K, Vonhof MJ, Cochran WW, Wikelski M (2006) Bat orientation using Earth's magnetic field. Nature 444:702

Hutterer R, Ivanova T, Meyer-Cords C, Rodrigues L (2005) Bat migrations in Europe: a review of banding data and literature. Bundesamt für Naturschutz, Bonn

Issel W (1950) Ökologische Untersuchungen an der Kleinen Hufeisennase (Rhinolophus hipposideros (Bechstein)) im mittleren Rheinland und unteren Altmühltal. Zool Jahrb Abt Syst Oekol Geogr Tiere 79:71-86

IUCN (1998) Guidelines for re-introductions. Prepared by the IUCN/SSC Re-introduction Specialist Group. IUCN, Gland and Cambridge

Jones G, Duvergé PL, Ransome RD (1995) Conservation biology of an endangered species: field studies of greater horseshoe bats. Symp Zool Soc Lond 67:309-324

Jung TS, Thompson ID, Hickey MBC, Titman RD (2002) Apparent capture myopathy in Hoary bats, Lasiurus cinereus: a cautionary note. Can Field Nat 116:136-137

Kerth G, Safi K, König B (2002) Mean colony relatedness is a poor predictor of colony structure and female philopatry in the communally breeding Bechtein's bat (Myotis bechsteinii). Behav Ecol Sociobiol 52:203-210

Kramer RJ (1971) Hawaiian land mammals. Charles E. Tuttle Company, Rutland, VT

Letty J, Marchandeau S, Clobert J, Aubineau J (2000) Improving translocation success: an experimental study of antistress treatment and release method for wild rabbits. Anim Conserv 3:211-219

Lugon A (1996) Ecologie du grand rhinolophe, Rhinolophus ferrumequinum (Chiroptera, Rhinolophidae) en Valais (Suisse): habitat, régime alimentaire et stratégie de chasse. MS thesis, University of Neuchâtel

Mickleburgh SP, Hutson AM, Racey PA (2002) A review of the global conservation status of bats. Oryx 36:18-34

> Norris K (2004) Managing threatened species: the ecological toolbox, evolutionary theory and declining-population paradigm. J Anim Ecol 41:413-426

Ransome R (1995) Earlier breeding shortens life in female greater horseshoe bats. Philos Trans R Soc Lond 350: 153-161

Richarz K (1989) Report of the successful transplantation of a nursery colony of the lesser horseshoe bat (Rhinolophus hipposideros) and remarks about the actual status of this species in Bavaria. In: Hanak V, Horacek I, Gaisler J (eds) European bat research 1987. Charles University Press, Prague, p 659-670

Roer H (1983) Zur Bestandssituation von Rhinolophus ferrumequinum (Schreber, 1774) und Rhinolophus hipposideros (Bechstein, 1800) im westlichen Mitteleuropa. Myotis 21-22:122-131

Ruffell J, Parsons S (2009) Assessment of the short-term success of a translocation of lesser short-tailed bats 
Mystacina tuberculata. Endang Species Res 8:33-39

Schaub M, Gimenez O, Sierro A, Arlettaz R (2007) Enhanced estimates of population dynamics obtained from limited data. Conserv Biol 21:945-955

Schaub M, Zink R, Beissmann H, Sarrazin F, Arlettaz R (2008) When to end releases in reintroduction programmes: demographic rates and population viability analysis of bearded vultures in the Alps. J Appl Ecol 46: 92-100

Seddon PJ (1999) Persistence without intervention: assessing success in wildlife reintroductions. Trends Ecol Evol 14: 503

Sierro A, Lugon A, Arlettaz R (in press) La colonie de grands rhinolophes Rhinolophus ferrumequinum de l'église StSylve à Vex (Valais, Suisse): évolution sur deux décennies (1986-2006). Le Rhinolophe

Stebbings RE (1982) Radio tracking greater horseshoe bats

Editorial responsibility: Stephen Rossiter,

London, UK with preliminary observations on flight patterns. Symp Zool Soc Lond 49:161-173

Stebbings RE, Arnold HR (1989) Preliminary observations of 20th century changes in distribution and status of Rhinolophus ferrumequinum in Britain. In: Hanak V, Horacek I, Gaisler J (eds) European bat research 1987. Charles University Press, Prague, p 559-563

Stutz HP, Haffner M (1984) Arealverlust und Bestandesrückgang der Kleinen Hufeisennase Rhinolophus hipposideros (Bechstein, 1800) (Mammalia: Chiroptera) in der Schweiz. Jahresber Natforsch Ges Graubünden 101:169-178

White GC, Garrott RA (1990) Analysis of wildlife radio-tracking data. Academic Press, San Diego, CA

Williams ES, Thorne ET (1996) Exertional myopathy (capture myopathy). In: Fairbrother A, Locke LN, Hoff GL (eds) Noninfectious diseases of wildlife, 2nd edn. Manson Publishing, London, p 181-193

Submitted: April 18, 2008; Accepted: March 5, 2009

Proofs received from author(s): May 1, 2009 